\title{
Correction to: Emergence of phenotypic and genotypic resistance in the intestinal microbiota of rainbow trout (Oncorhynchus mykiss) exposed longterm to sub-inhibitory concentrations of sulfamethoxazole
}

\section{Rachael N. Labitt ${ }^{1} \cdot$ Jennifer Ren ${ }^{1} \cdot$ Hélène Marquis (iD ${ }^{1}$}

Published online: 15 October 2021

(c) Springer Science+Business Media, LLC, part of Springer Nature 2021

Correction to: Ecotoxicology (2021)

https://doi.org/10.1007/s10646-021-02480-9

In the original publication of the article, the authors noticed that Supplementary Tables 2, 3, 4, and Supplementary Figure 1 are missing in the supplementary material files. This has been corrected with this erratum.

The original article can be found online at https://doi.org/10.1007/ s10646-021-02480-9.

Supplementary information The online version contains supplementary material available at https://doi.org/10.1007/s10646021-02491-6.

Hélène Marquis

hm72@cornell.edu

1 Department of Microbiology and Immunology, Cornell University, Ithaca, NY 14853, USA
The original article has been corrected.

Publisher's note Springer Nature remains neutral with regard to jurisdictional claims in published maps and institutional affiliations. 